\title{
SIMULATION OF RANDOM TAGGED ORE FLOW THROUGH THE BUNKER IN A BELT CONVEYING SYSTEM
}

\author{
Bardzinski, P. J. ; Walker, P.; Krol, R. \& Kawalec, W. \\ Faculty of Geoengineering, Mining and Geology, Wrocław University of Science and Technology, \\ ul. Na Grobli 13/15, 50-421 Wrocław, Poland \\ E-Mail: piotr.bardzinski@pwr.edu.pl ("Corresponding author)
}

\begin{abstract}
Modelling the flow of a non-homogeneous ore is an important element needed to identify ore parameters for the purpose of ore processing control. The simulation model of the underground ore haulage system with the implemented function of estimating ore qualitative and quantitative parameters was built in the dedicated FlexSim simulation environment to address this issue. The transported ore is averaged in transfer and retention points, for instance in ore bunkers. This fact renders the modelling of ore flow inside the bunker a necessary part of the simulation. The movement of the granulated material, restricted by the geometry of the floor and walls, is modelled using Discrete Elements Method (DEM) with regard to the technological cycles of bunker filling and emptying. An experimental task was conducted on the site to identify the transport time of RFID tags that flowed together with the portions of ore they annotated. Empirical model of the transport system in the KGHM Lubin mine was parameterized with mean retention times obtained in DEM simulations in order to be compared with the RFID-tag experiment. The as-parameterized FlexSim simulation for one-chute bunker discharge variant yields tag transport times comparable with the experimental data. The results proved the reliable description of the ore transport time in the FlexSim model.

(Received in March 2018, accepted in August 2018. This paper was with the authors 1 week for 1 revision.)
\end{abstract}

Key Words: Discrete Elements Method, FlexSim, Empirical Model, RFID, Ore Transport, Ore Bunker

\section{INTRODUCTION}

Acquiring, processing and transporting of any non-homogenous raw bulk material causes specific problems to the industry as the material quality parameters need to be controlled in order to match established requirements of the final products. In the mining industry a lot of efforts is undertaken to control blending of a run-of-mine mineral [1]. Modern mining plants use advanced software to build 3D quality orebody models. Such plants also use tools enabling them to plan extraction and even optimize the advance of mine faces in order to ensure that run of mine ore has certain quality parameters desired by the customers [1-3]. In copper ore mines, this means extracting ore having grades described in official regulations. This quality can be determined in the deposit, with certain accuracy, by prior sampling: sinking drill holes from the surface, drilling protection holes, taking chip samples or performing development works. The accuracy depends on ore structure, concentration of drill holes, ore sampling frequency, and the employed interpolation methods (e.g. geostatistical). Problems with quality assessment occur when mined ore is blended, e.g. after the whole mined deposit height is blasted, or when ore is transported, e.g. on a belt conveyor with many feeding points and in transfer stations $[4,5]$. The identification of a transported run-of-mine ore is a compulsory condition to implement the Quality Assurance - Quality Control (QA/AC) procedures, necessary to maintain the required quality of products as well as to reconcile the mining production in mining fields.

Ore extraction, storage and transport pose a typical production planning problem faced by various branches of industry [6-9]. Without the ability to selectively work and transport the material, and without solutions ensuring reliable delivery (duplicated conveyor lines, retention 
bunkers, transfer stations, alternative delivery routes) it is impossible to control the quality of the transported ore. This control may be restored if ore is annotated with special RFID markers and if its flow is controlled in selected locations (via sensors), or if simulated ore flow (its quantity and composition) is actively followed to model actual conditions. Although the problem was successfully addressed using various modelling packages, the latter task may be performed with the use of the FlexSim software, which enables simulating both cyclical and continuous operation of transportation systems [10-12].

Part of the DISIRE project [13-16] was to develop such a model of ore flow in the underground transportation system, which would enable simulation of the experimental flow of Radio-Frequency Identification (RFID) markers, termed here as pellets, according to their physical shape. Such approach allows testing the potential for the proposed application of the intelligent bulk material stream technology, whose general concept can be described to cover the following procedure: analyse input (both qualitative and quantitative) ore parameters, record the information in the RFID sensor, add the sensor to the transported bulk material, transport the bulk material together with the sensors, read the information from the sensors, process it and use it to facilitate ore processing control in the Ore Concentration Plants [13, 14]. The significance of the project lies in the fact that the copper ore beneficiation processes in the KGHM company are highly energy consuming and their effectivity (e.g. of grinding) depend on the actual ore compound (the energy used for grinding can vary to $50 \%$ for different mixes of the grinded ore [15]). Obtaining in advance information on the quality of the ore fed to the processing plants may contribute to improve the efficiency of the energyintensive operations such as preparing ore for flotation, i.e. crushing and milling [15].

When following ore flow with the annotating pellets, an additional task consists in identifying the flow of pellets together with the portions of annotated ore along the length of haulage lines. Particular attention must be paid to accurate modelling of ore behaviour in the nodes of the transportation system, i.e. in the bunkers. The bunkers, apart from serving a retention function, also affect the averaging of ore parameters, as the portions of mined material subsequently added to the bunker change their position and mix. Thus, the task is complicated and the analytical methods used so far, which are based on numerous generalizations and simplifications and which treat mined ore as continuous material, did not allow full representation of actual conditions [16]. Therefore, the modelling of the behaviour of ore inside the bunker was based on Discrete Element Method (DEM), which uses Newton's second law and adequate contact models to analyse bulk material with regard to its particulate nature. The method was chosen as it found recent application in modelling industrial processes, e.g. solid particles in dredging excavation and particle flow in rock cutting [17]. This in turn allowed analysing the results of multi-variant simulations modelling of ore flow through a retention bunker with regard to the technological cycles of bunker filling and emptying. The current study presents parameterized, variant streams of ore flow through the bunker, with optional pellets, as conditioned by technological data: ore feed (granulation, efficiency of input stream), bunker structure (geometry, discharge technology) and delivery (bunker fill degree, output stream efficiency), simulated for the analysed large-capacity shaft station bunker located in an underground copper ore mine [18-20].

Empirical model of the transport system in the ZG Lubin mine was built within the FlexSim program [12]. The experiment was conducted in the actual mine in order to assess the accuracy of the model. Pellets with the ascribed source number, were dropped by each of three staff members at the locations shown in Fig. 1. Physical appearance of the tags together with one of the dropping points during in situ experiments were shown in Fig. 2. Pellets were dropped every minute within $1.65 \mathrm{~h}$ and recorded by the tag-detecting antennae system placed before the Ore Enrichment Plant. The RFID-tag reading ended after $36.8 \mathrm{~h}$. The corresponding 3D model in FlexSim was parameterized according to experimental conditions. 


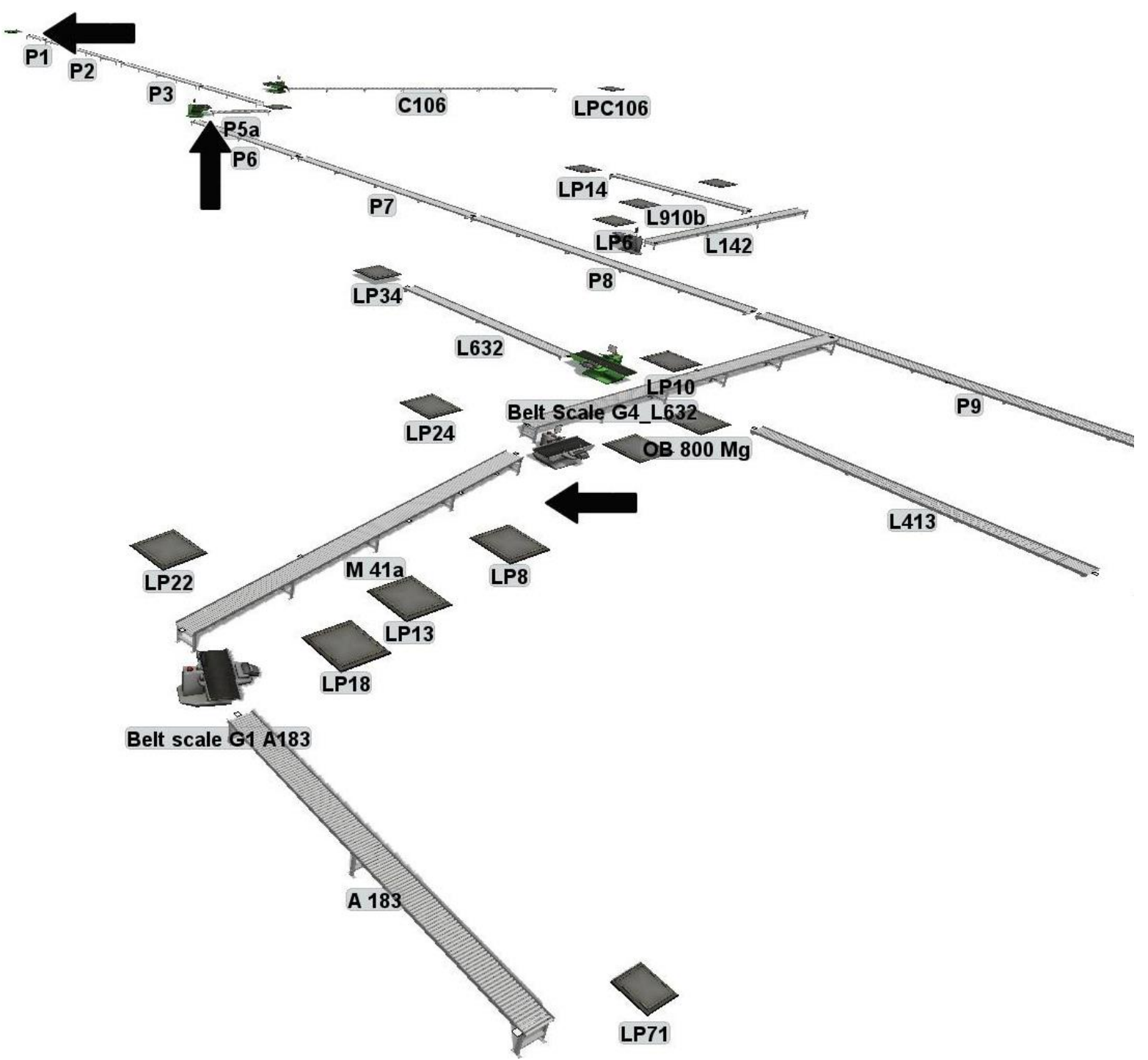

Figure 1: Graphical representation of ZG Lubin mine model part in Flexsim, indicating three pellet dropping points (marked with arrows).
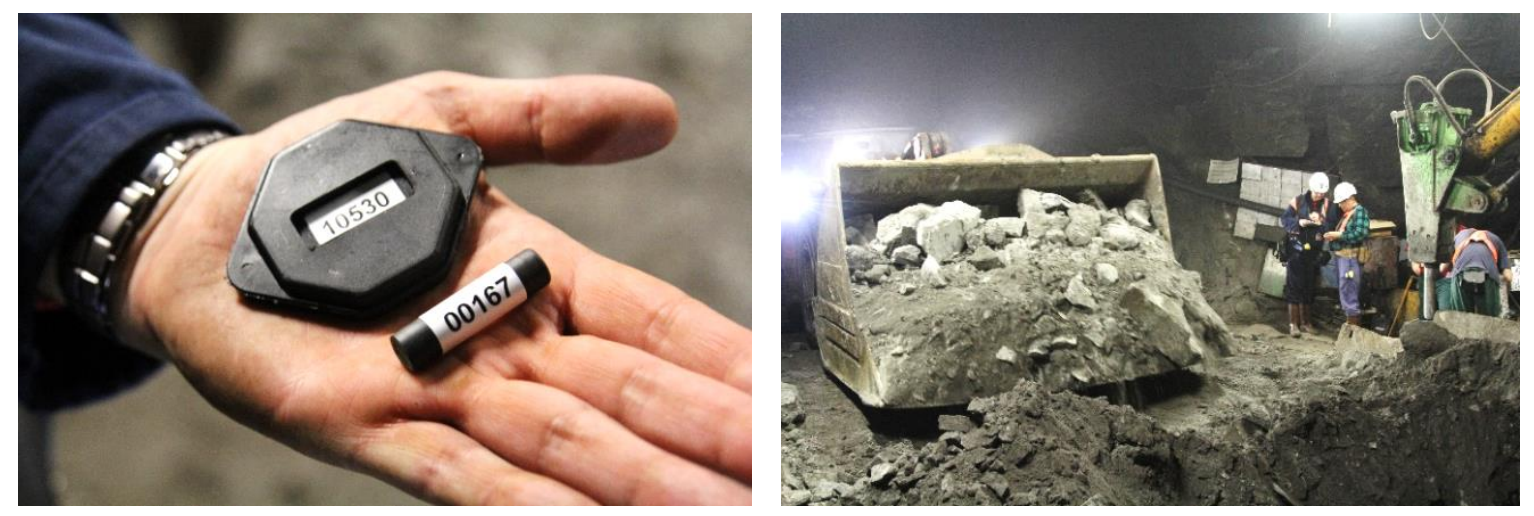

Figure 2: Physical appearance of the pellet (left) and actual dropping point (right).

\section{DESCRIPTION OF THE SIMULATION ENVIRONMENT}

In the case of continuous transportation via belt conveyors it is important to have material retention points. When one element of the conveyor system is out of service, mined material may be stored until the service is restored. Additionally, material retention separates the 
division transportation systems from the main transportation system, and as a result allows the machines and other devices operated in the mining divisions to work at full capacity. The use of ore retention (surge) bunkers also allows the levelling of ore stream fed from individual mining divisions. Surge bunkers are built in the vicinity of shafts and have high storage capacity which ensures continuous operation of skips, while also acting as a storage location for mined ore delivered to processing plants over the periods when mining works are interrupted.

The planned simulations involved modelling the shaft station bunker in Lubin mine, whose location in the transportation line is shown in Fig. 3. Ore is fed to the bunker with the use of a boom conveyor located on the P1 belt conveyor whose capacity is approximately $800 \mathrm{Mg} / \mathrm{h}$. This conveyor is the last element of a conveyor line constituting the main haulage system and transporting ore delivered from the Lubin East EW II area. The modelled surge bunker is the last retention station and provides storage capacity of approximately $1040 \mathrm{Mg}$ (1.5 hour of continuous delivery). By using the force of gravity, it spreads ore into two belt conveyors, which then feed the ore to crushers and then, through the measurement bins, is fed directly to the skips. The bunker was built in the ore-bearing rock and thus its main part does not have a housing. In the bottom part of the bunker, in the spots which are most prone to damage, a protective lining was installed, made of used steel rails. The bunker feeds ore through a hopper tray which has discharge capacity of $350-400 \mathrm{Mg} / \mathrm{h}$, depending on ore fragmentation degree. As the tray performs approximately 3600 deliveries per one hour, its capacity may be calculated to be approximately $100 \mathrm{~kg}$ of material. If assumed that two trays are work simultaneously, the hopper discharge capacity is approximately $200 \mathrm{~kg} / \mathrm{s}$. The trays operate on a zero-one basis, i.e. they deliver ore with full capacity or they do not deliver it at all. No intermediate states occur in this process. The decision to open or close a particular tray in the bunker chute belongs to the operator, whose task is to ensure continuous operation of the skip. The bunker is typically not filled to its capacity and the material is fed continuously. Due to safety regulations, the bunker may be filled to a maximum of $85 \%$. The fill level is related to the angle of slide for copper ore. Contact limit sensor switches in the form of short circuit electrodes constitute the feeding conveyor protection system.

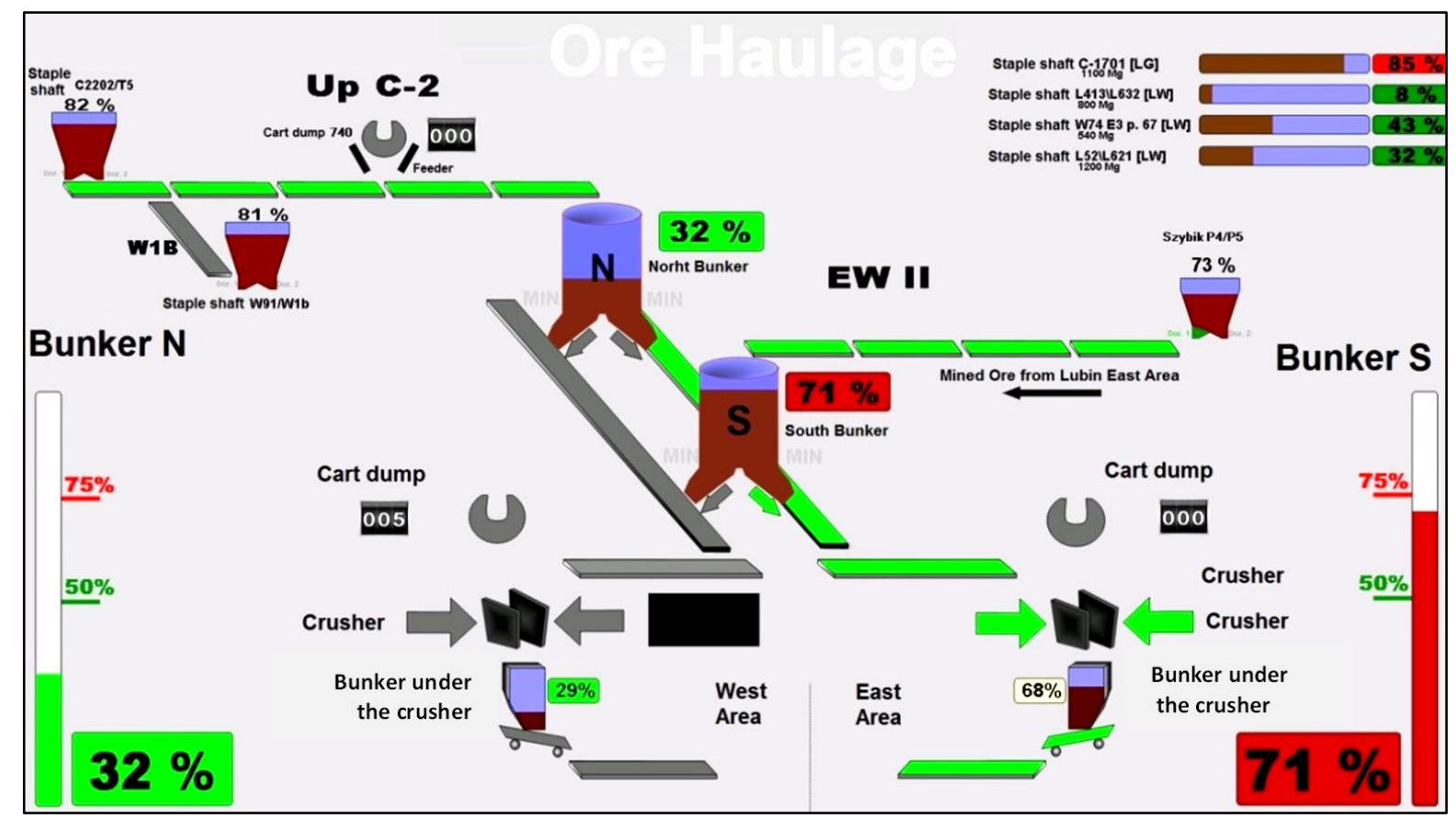

Figure 3: Scheme of cooperation between Lubin East Area conveyor network (EW II) with skip shaft (surge) bunkers (Source: Lubin Mine). 


\section{TEST METHODOLOGY}

The key characteristics of the simulations performed in DEM tool that allowed investigation of the mechanisms involved in the movement of ore particles during the process of bunker filling and emptying included:

- developing a model of the shaft surge bunker, on the basis of its vertical and horizontal cross-sections recorded in situ by means of laser scanning method,

- modelling a fragment of the belt installed on the belt conveyor boom, which feeds mined ore to the bunker, reconstructing the actual dimensions and location in order to obtain natural discharge trajectory,

- modelling ore particles on the basis of grain size distribution slope for the analysed ore,

- adjusting strength parameters for the materials used in the simulation (copper ore, pellets, bunker lining, steel chute, conveyor belt),

- selecting an adequate interaction model and its parameters in order to model the principles of the behaviour of the transported material.

Using the developed simulation model, an attempt was made to identify the pellet flow times, together with the portions of material, for two variants of bunker emptying, i.e.:

- variant 1 - for the case with one chute open (right),

- variant 2 - for both chutes open simultaneously (left and right).

The behaviour of pellets was at the same time analysed for various bunker fill levels. For this purpose, five pellets dropped into the bunker were manually selected for each bunker fill level, observing the order in which they fall and the directions in which they move in the bunker. The pellets selected for analyses are shown in Fig. 4 a. In both investigated emptying variants, the analysis of flow times through the bunker was performed for the same pellets, adequately assigned to each bunker fill level (Figs. $4 \mathrm{~b}$ and $4 \mathrm{c}$ ). In the next step, by playing the simulation for a number of times, the flow time for each pellet was determined, as was the flow path and the order in which pellets were discharged.
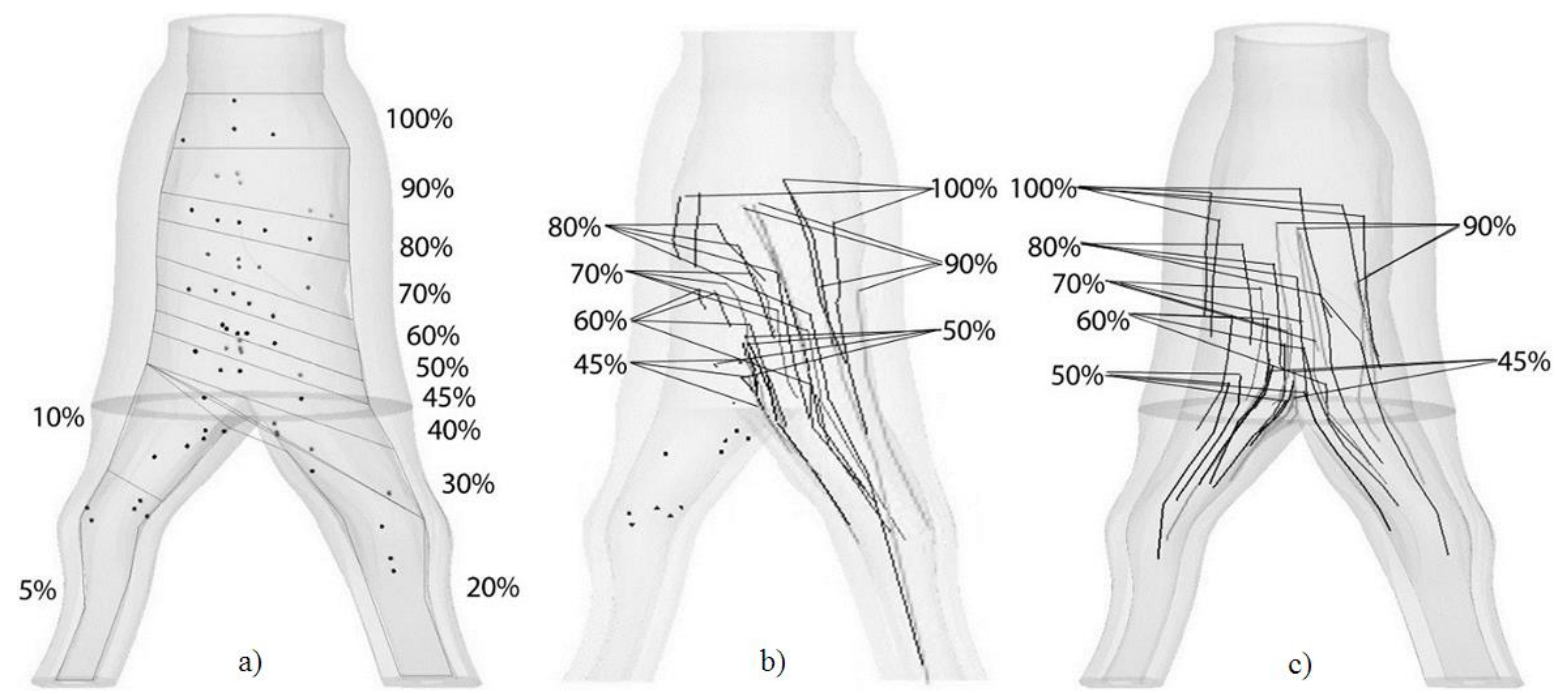

Figure 4: Location of pellets at various bunker fill stages (a) and the flow path in a simulation with one chute (b) and with two chutes open (c).

As the simulation did not include the trays operated in the chutes, material was discharged from the model bunker at a much faster pace than in actual conditions. Therefore, in order to identify the actual pellet flow times, a series of calculations was performed, which allowed finding how many times faster each numerical simulation progressed. For this purpose, knowing the operating capacity of one tray $(350 \div 400 \mathrm{Mg} / \mathrm{h})$ and the maximum bunker 
capacity (1040 Mg), the time needed to completely empty the bunker was calculated (approximately 1 hour 39 minutes). In the next step, knowing the mass of the material stored in the simulation and the emptying time, it was possible to determine the emptying efficiency of the bunker modelled in the EDEM application $(24.5 \mathrm{Mg} / \mathrm{s})$. In the simulation with one open chute, the value of mass was reduced by the amount of material which remained in the bunker. Thus, it was possible to determine acceleration factors $a_{p}$, which served, along with the simulation results, to find actual pellet flows for both bunker emptying variants. In the case of the variant with one open chute, factor $a_{p 1}=117.60$, while in the variant with two open chutes, the $a_{p 2}=153.06$.

DEM simulations performed in the current study encompassed modelling of five materials, constituting the conveyor belt, housing of the main part of the bunker, the orebearing rock, steel chutes, the sulphide copper ore, as well as the pellets made of PET. Strength parameters of the mentioned materials were based on the literature sources [21-24] and collected in Table I. Each type of the simulated particles was provided with values describing their interactions with other materials in the simulation, as given in Table II. The reflection coefficient was equal to 0.01 for ore and pellet interaction with all involved materials.

Table I: Materials strength parameters utilized in DEM simulations.

\begin{tabular}{|l|c|c|c|c|c|}
\hline Parameter & Copper ore & Pellet & Bunker housing & Steel chute & Conveyor belt \\
\hline Poisson ratio $[-]$ & 0.2 & 0.35 & 0.22 & 0.285 & 0.5 \\
\hline Young's modulus $[\mathrm{GPa}]$ & 22.54 & 2.28 & 36.32 & 190 & 0.01 \\
\hline Volume density $\left[\mathrm{kg} / \mathrm{m}^{3}\right]$ & 2565 & 1500 & 2565 & 7860 & 2000 \\
\hline
\end{tabular}

Table II: Interactions between pellet and other simulated materials.

\begin{tabular}{|c|c|c|c|c|}
\cline { 2 - 5 } \multicolumn{1}{c|}{} & \multicolumn{2}{c|}{ Ore interactions } & \multicolumn{2}{c|}{ Pellet interactions } \\
\hline Material & $\begin{array}{c}\text { Coefficient of } \\
\text { restitution }\end{array}$ & $\begin{array}{c}\text { Static friction } \\
\text { coefficient }\end{array}$ & $\begin{array}{c}\text { Reflection } \\
\text { coefficient }\end{array}$ & $\begin{array}{c}\text { Static friction } \\
\text { coefficient }\end{array}$ \\
\hline Conveyor belt & 0.1 & 0.65 & 0.1 & 0.7 \\
\hline Bunker housing & 0.1 & 0.75 & 0.2 & 0.2 \\
\hline Ore & 0.1 & 0.75 & 0.2 & 0.2 \\
\hline Steel & 0.1 & 0.3 & 0.2 & 0.3 \\
\hline Pellet & 0.2 & 0.2 & 0.3 & 0.2 \\
\hline
\end{tabular}

FlexSim simulation time was set to $132600 \mathrm{~s}$, what is equivalent to $36 \mathrm{~h} 50 \mathrm{~min}$. Skips as well as every belt conveyor in the system were scheduled on 24-hour basis. The belt conveyors were working every day except maintenance and rock-blasting breaks from 5:00 to 7:00 AM and at 6:00 PM. Down time of the skips was scheduled from 6:00 to 11:00 PM. Duration of loading cycle of each skip was set to $176 \mathrm{~s}$ and their maximum speed was set to $16 \mathrm{~m} / \mathrm{s}$. Each pellet was introduced into the system every $60 \mathrm{~s}$, from the beginning to $5940 \mathrm{~s}$ of the simulation.

\section{RESULTS AND DISCUSSION}

A pellet flow time was determined for each of the investigated bunker fill levels. Additionally, the pellets were assigned a number corresponding to the order in which they were dropped into the bunker (from 1 to 5). The results of the investigations are shown in Fig. 
5. Squares represent the pellets used in the simulation with two open chutes, while circles (dots) represent pellets used in the variant with one open chute.

In the variant with two simultaneously open chutes, pellet flow times through the bunker were shorter for each of the bunker fill levels. This phenomenon was influenced by higher bunker emptying efficiency, as well as by a shorter flow path (Fig. $4 \mathrm{c}$ ).

When analysing the behaviour of individual pellets, it must be noted that their majority was discharged from the bunker in the order different from the order in which they entered the bunker. The decisive factor in this case was the direction in which the simulated material having various size distribution rebounded and rolled down the natural conical pile formed due to the discharge trajectory from the feeding conveyor. In both variants, material acceleration was also observed at the bunker outside walls.

a)

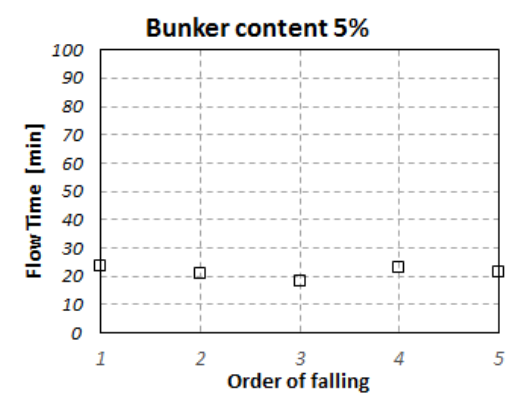

d)

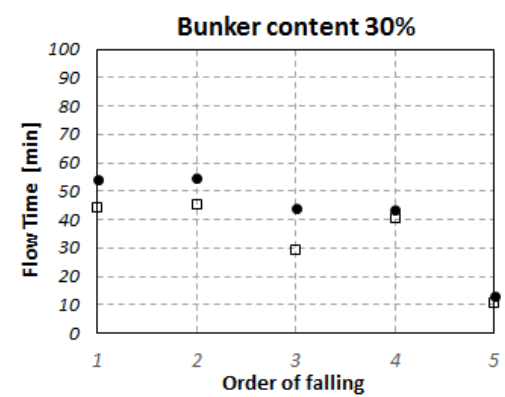

g)

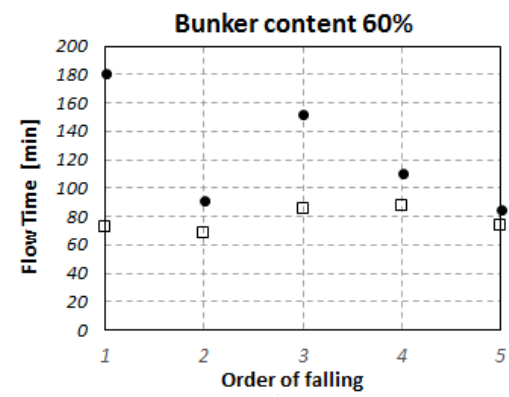

b)

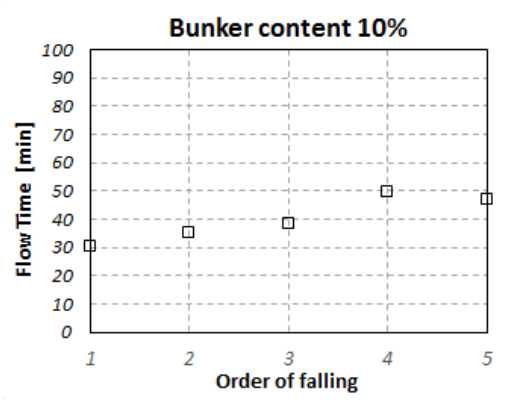

e)

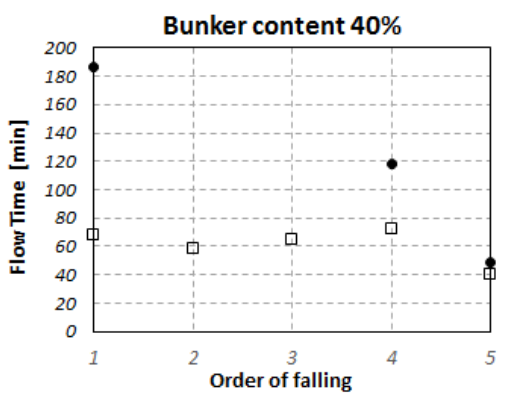

h)

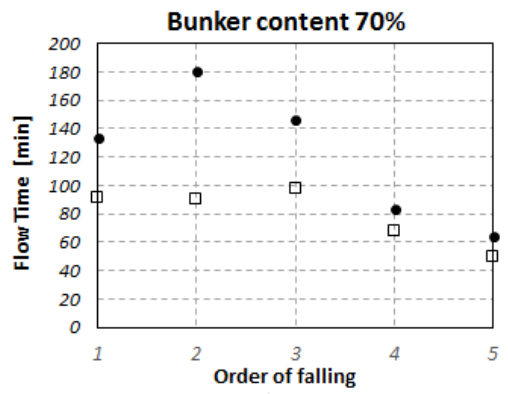

j)

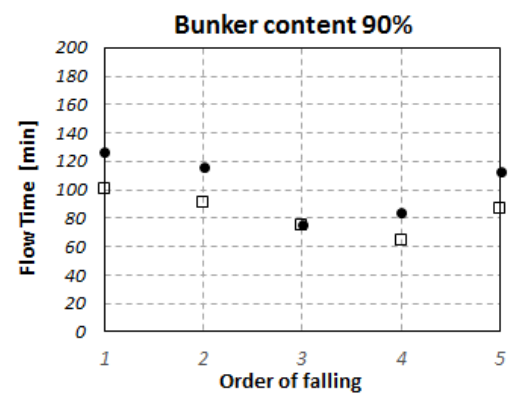

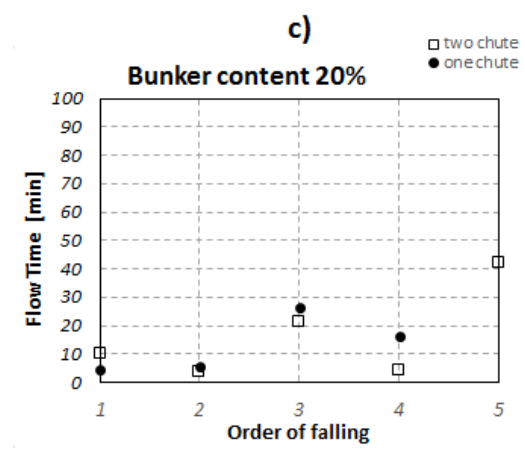

f)

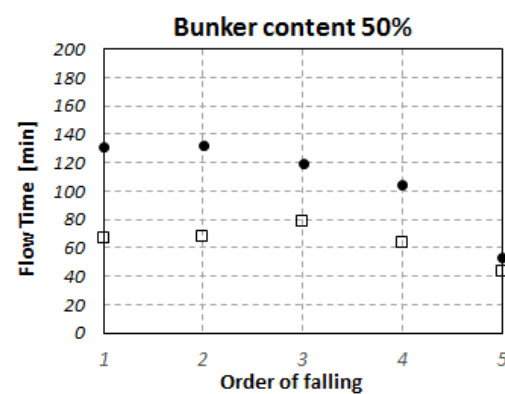

i)

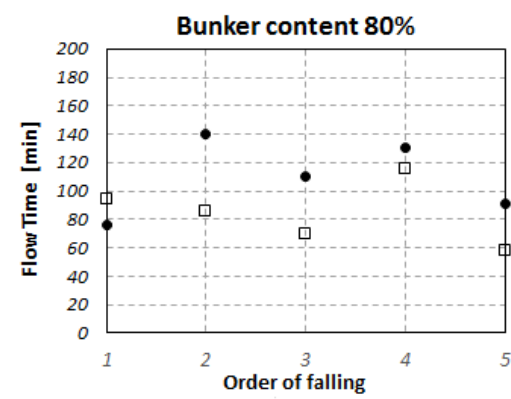

k)

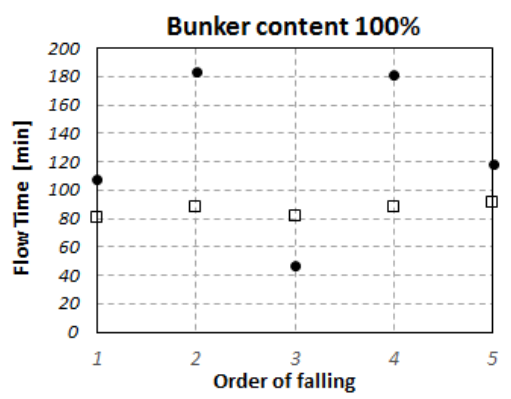

Figure 5: Pellet flow times measured for the selected variants of bunker emptying. 
In Figs. $5 \mathrm{a}$ and $5 \mathrm{~b}$, only those pellets were indicated which were used in the simulation for variant 1 , as at $5 \%$ and $10 \%$ bunker fill level the mined ore is dropped only to the left chute and is not discharged in the considered case of emptying only the right chute. An interesting situation was observed at subsequent filling stages. For $20 \%$ fill level (Fig. $5 \mathrm{c}$ ) four out of five pellets in variant 1 left the bunker, while one pellet remained on the natural conical pile. In the case of $30 \%$ fill level (Fig. 5 d) all pellets were discharged from the bunker, as they were already located in the right chute. The situation was different in the case when the bunker was filled at $40 \%$ level, when only three pellets left the bunker, out of which one pellet was discharged at the very end of the emptying process. Such a behaviour is caused by the forming of the first layer filling the bunker proper (not the chute), in which the ore located over the right chute leaves the bunker first, the ore located in the middle part leaves the bunker last, and the ore located over the left, closed chute is not discharged, forming a natural conical pile. In the subsequent filling stages, significant discrepancies can be observed between the flow times for both analysed variants, which are obviously due to the difference in the bunker emptying method.

Moreover, for the variant with one open chute, the pellets delivered to the bunker at later filling stages (from approximately $70 \%$ ) frequently leave the bunker earlier than the pellets dropped at earlier filling stages. This phenomenon is well illustrated in Fig. 6, which shows individual bunker emptying stages in the variant with right chute open.

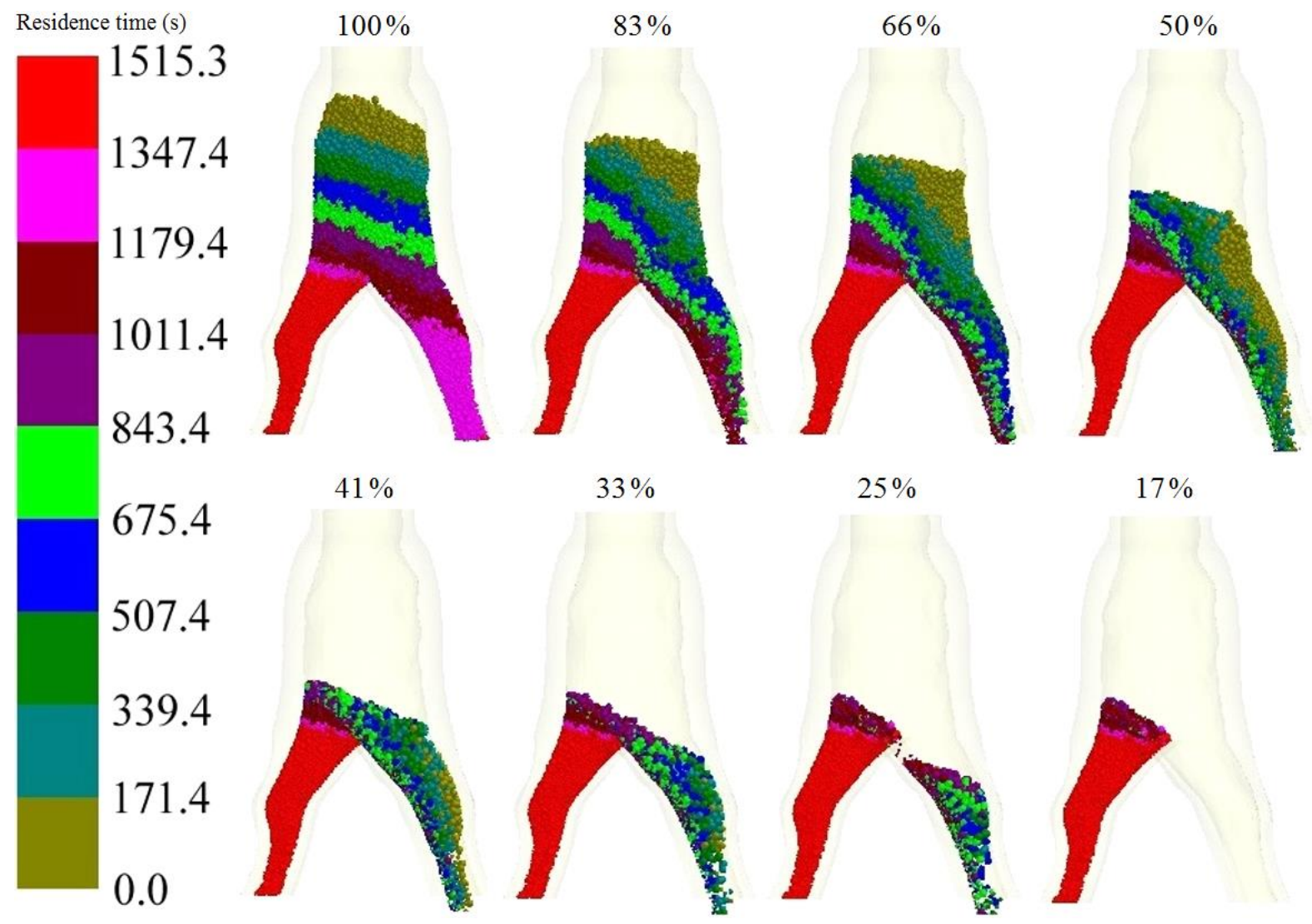

Figure 6: Ore flow during bunker emptying process in the variant with one open chute.

The ore located on the side of the open chute leaves the bunker first, in the next step the ore located in the upper layers on the left starts to move towards the right side, heading towards the empty space left behind the ore which had been already discharged from the bunker.

It was found that among many factors contributing to ore portion or pellet transport time in the underground mine, such as schedule of conveyor systems and skips, the one of the 
major was the retention time in the ore bunker. In the considered case, it is South Ore Bunker No. 214, represented in the FlexSim model by the Processor (graphically depicted as Queue $3 \mathrm{D}$ object) and its chutes by the Separator object in the model shown in Fig. 2. Mean retention time versus bunker content was compared for both variants and presented in Fig. 7.

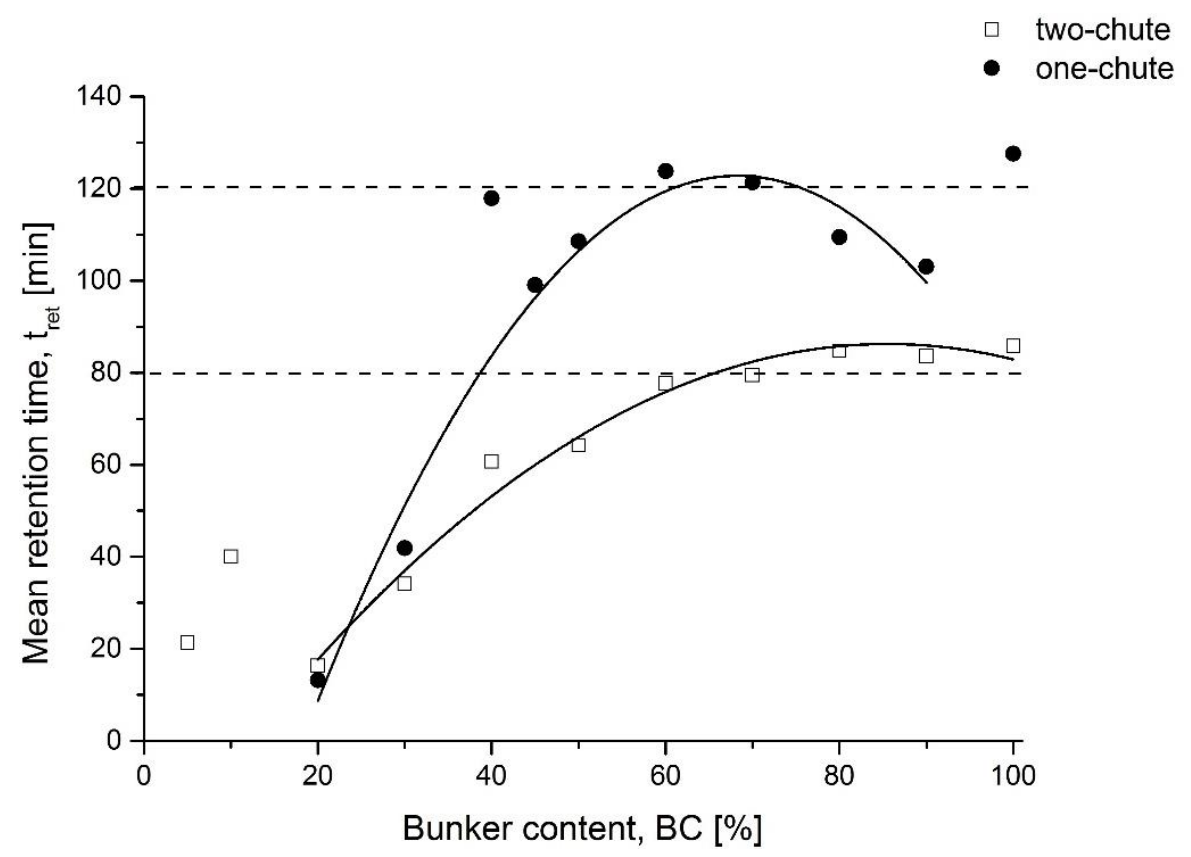

Figure 7: Mean retention time for two Edem simulation variants: ore flow through one- and two-chute South Ore Bunker No. 214.

In the case of bunker emptying in two-chute variant, at $20 \%$ bunker fill level, a significant decrease of pellet flow time can be observed. This is due to the fact that after the first chute is filled, ore starts to pour to the second chute, and as a result it travels a shorter path to the discharge point. No other major issues were observed in the further part of the plot. Solid lines on the graph are the data fit with second-order polynomial, according to the Eq. (1):

$$
t_{\text {ret }}=A_{1}+A_{2} B C+A_{3} B C^{2}
$$

with the parameters collected in Table III. Adjusted coefficients of determination $R^{2}$ obtained for both bunker discharge variants show good approximation with the chosen function.

Table III: Polynomial fit of mean retention time versus bunker content functional dependencies presented in Fig. 7.

\begin{tabular}{|c|c|c|c|c|}
\hline Variant & $\boldsymbol{A}_{\mathbf{1}}$ & $\boldsymbol{A}_{\mathbf{2}}$ & $\boldsymbol{A}_{\mathbf{3}}$ & Adj. $\boldsymbol{R}^{\mathbf{2}}$ \\
\hline one-chute & $-105.41 \pm 13.10$ & $6.69 \pm 0.52$ & $-4.90 \mathrm{E}-02 \pm 4.67 \mathrm{E}-03$ & 0.9762 \\
\hline two-chute & $-30.68 \pm 7.53$ & $2.73 \pm 0.28$ & $-1.60 \mathrm{E}-02 \pm 2.29 \mathrm{E}-03$ & 0.9735 \\
\hline
\end{tabular}

Dashed lines in Fig. 7 stand for the mean retention time with the bunker content between $60-80 \%$. Assuming such level of bunker occupancy, occurring within the majority of the object's operational time, two values of mean retention time of the Ore Bunker S214 were included in the FlexSim model, 80 and $120 \mathrm{~min}$ for two-chute and one-chute bunker discharge, respectively.

The results of the two variants of FlexSim simulation compared with the experiment conducted in-situ are presented in Fig. 8. The abscissa represents the time, given in hours, at which the pellet dropped at each point was recorded by the tag readers before the OEP. In the 
experiment, pellet dropped at the conveyors P1 and P5 exhibit leftness of its triangular distribution of the read times. This feature also appeared in case of P1 pellets in both FlexSim simulation variants. Gaussian-like distribution was observed for the experimental read times of M41a pellets. Choice of one-chute discharge mode in the simulation leads to proper description of the experimental ore transport times, at least in the left and middle part of the histograms, concerning the majority of the recorded RFID tags. In case of the right side of the histograms, the observed differences may occur eg. due to sticking of the tags to the mud, what was not taken into account in the model. In case of M41a pellet, both in the experiment and in the simulation at one-chute variant, some of the pellets needed $18 \mathrm{~h}$ to reach the OEP. As it takes more time to discharge the Ore Bunker S214 in this variant, some of the pellets from the furthermost M41a conveyor can wait in the end of the queue or, in the real conditions, at the top of the ore pile in the bunker for a longer period of time. Most of the pellets needs from 3 to $13 \mathrm{~h}$ to reach the OEP, depending on their dropping point.

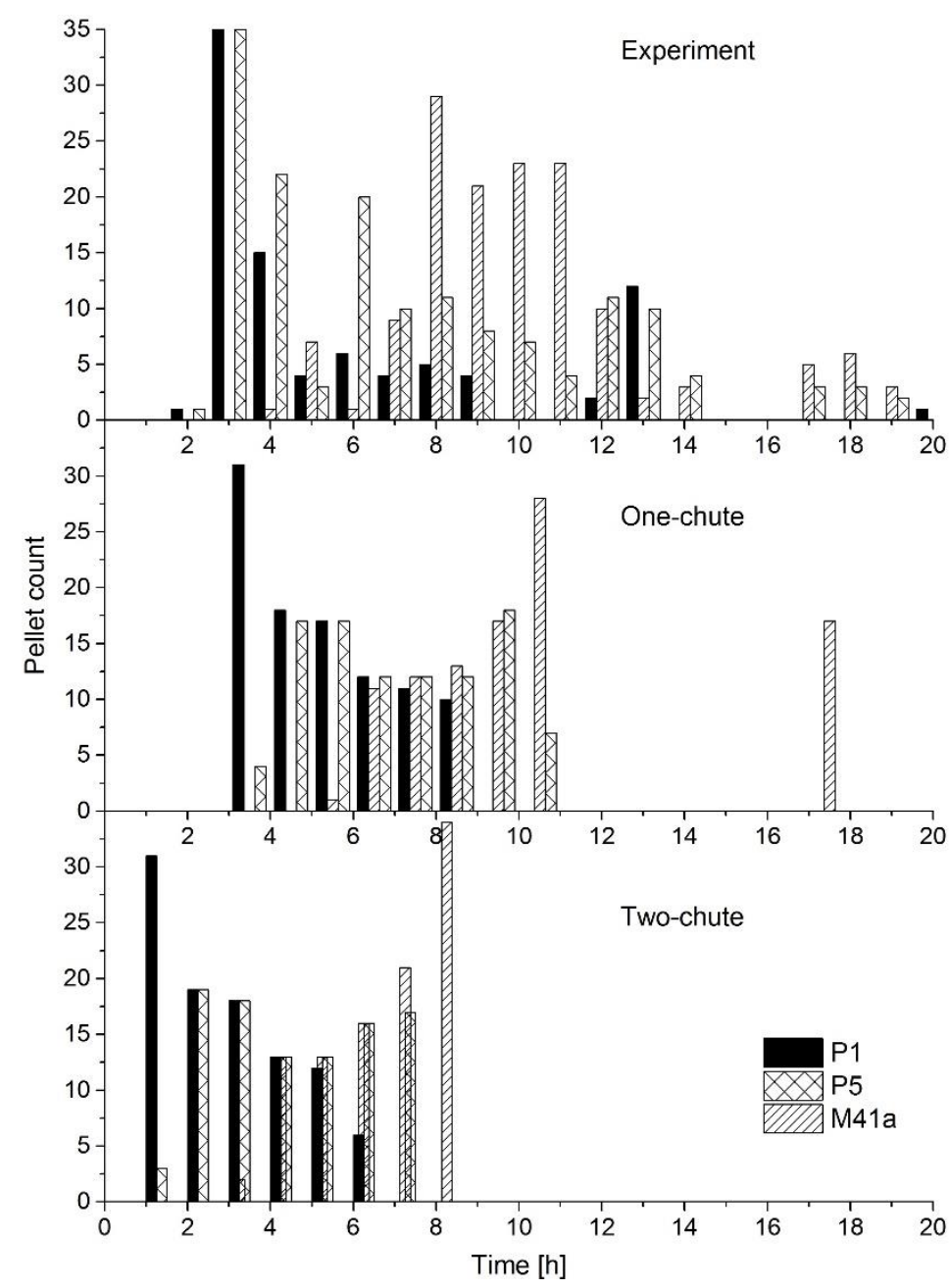

Figure 8: Comparison of experimental data with the FlexSim simulation considering one- and twochute ore release in South Ore Bunker No. 214.

\section{SUMMARY AND CONCLUSIONS}

The current study presents parameterized, variant streams of ore flow through the shaft (surge) bunker, which depends on the technological conditions governing the filling and emptying of the bunker. Three-dimensional geometry of the inside of the rock-carved bunker was recorded by means of laser scanning method. Then, Discrete Element Method (DEM) 
model of the bunker was made using the EDEM software package. This approach allowed following the movement of each of the analysed pellets and use this data to determine their flow times through the bunker for two variants considered, depending on ore discharge scheme, i.e., by one or two chutes, that were opened or closed by the mine personnel.

Mean ore retention times were described by approximating the averaged pellet flow time values obtained for each of the assumed bunker fill levels with second-order polynomial.

Apart from analysing ore flow times through the bunker, the developed simulation model allowed a closer investigation into the phenomena which occur as individual fractions flow through the bunker, as well as into the behaviour of mined material during the process of bunker filling and emptying with one chute open.

For the model idealized to an assumed degree, it was possible to acquire data needed to parameterize selected elements of the model which simulates ore flow in the underground transportation system, and which was developed, as part of the DISIRE project at the Wroclaw University of Science and Technology. Although the results obtained from the simulations are satisfying, further research is performed in order to improve the model inter alia by fully simulating the operation of the trays located in the chutes. Moreover, it is planned to reduce the idealization level of the model by giving shape to ore particles, reducing the minimum radius of a particle and better adjusting the interaction coefficients.

It was found that, the ore retention or time delay due to the transport through the ore bunker is an important model parameter that need to be adjusted in order to improve the description of the real conditions occurring in the mine. Empirical model of the transport system in the ZG Lubin mine was parameterized to be compared with the RFID-tag experiment conducted on the site. Discrete Element Method was applied to compute the mean retention time versus bunker content for the retention ore bunker through which the ore was flowing until it reach the OEP. One- and two-chute discharge variants were considered. The as-parameterized FlexSim simulation for one-chute variant yields correct tag transport time that corresponds to the experimental data. The results proved the reliable description of the ore transport time in the FlexSim model.

\section{ACKNOWLEDGEMENTS}

This work was partly supported by the Framework Programme for the Research and Innovation Horizon 2020 under the grant agreement No. 636834 (DISIRE) and by the Polish Ministry of Science and Higher Education as scientific project No. 0401/0131/17.

\section{REFERENCES}

[1] Benndorf, J. (2013). Application of efficient methods of conditional simulation for optimizing coal blending strategies in large continuous open pit mining operations, International Journal of Coal Geology, Vol. 112, 141-153, doi:10.1016/j.coal.2012.10.008

[2] Naworyta, W.; Sypniowski, S.; Benndorf, J. (2015). Planning for reliable coal quality delivery considering geological variability: A case study in Polish lignite mining, Journal of Quality and Reliability Engineering, Vol. 2015, Paper 941879, 9 pages, doi:10.1155/2015/941879

[3] Abdel Sabour, S.A.; Dimitrakopoulos, R. (2011). Incorporating geological and market uncertainties and operational flexibility into open pit mine design, Journal of Mining Science, Vol. 47, No. 2, 191-201, doi:10.1134/S1062739147020067

[4] Krzak, M.; Panajew, P. (2014). Value of geological information in exploitation management: the case of exploitation units of the Polkowice-Sieroszowice mine, Archives of Mining Sciences, Vol. 59, No. 1, 239-256, doi:10.2478/amsc-2014-0017

[5] Malega, P.; Kadarova, J.; Kobulnicky, J. (2017). Improvement of production efficiency of tapered roller bearing by using Plant Simulation, International Journal of Simulation Modelling, Vol. 16, No. 4, 682-693, doi:10.2507/IJSIMM16(4)10.405 
[6] Chen, M.-C.; Wu, H.-P. (2005). An association-based clustering approach to order batching considering customer demand patterns, Omega, Vol. 33, No. 4, 333-343, doi:10.1016/ j.omega.2004.05.003

[7] Muppani (Muppant), V. R.; Adil, G. K. (2008). Efficient formation of storage classes for warehouse storage location assignment: A simulated annealing approach, Omega, Vol. 36, No. 4, 609-618, doi:10.1016/j.omega.2007.01.006

[8] Zhang, G.; Tatsushi, N.; Turner, S. D. O.; Oga, K.; Li, X. (2017). An integrated strategy for a production planning and warehouse layout problem: Modeling and solution approaches, Omega, Vol. 68, 85-94, doi:10.1016/j.omega.2016.06.005

[9] Bendato, I.; Cassettari, L.; Mosca, M.; Mosca, R.; Rolando, F. (2015). New markets forecast and dynamic production redesign through stochastic simulation, International Journal of Simulation Modelling, Vol. 14, No. 3, 485-498, doi:10.2507/IJSIMM14(3)10.307

[10] Lavery, E.; Nordgren, B.; King, C.; Hullinger, R. (2005). Flexsim modeling environment, Proceedings of Asian Simulation Conference $/ 6^{\text {th }}$ International Conference on System Simulation and Scientific Computing, 1667-1670

[11] Wang, Y. R.; Chen, A. N. (2016). Production logistics simulation and optimization of industrial enterprise based on Flexsim, International Journal of Simulation Modelling, Vol. 15, No. 4, 732 741, doi:10.2507/IJSIMM15(4)CO18

[12] Jurdziak, L.; Kawalec W.; Król, R. (2017). Application of Flexsim in the DISIRE project, Studies \& Proceedings of Polish Association for Knowledge Management, No. 84, 87-96

[13] Kawalec, W.; Król, R.; Zimroz, R.; Jurdziak, L.; Jach, M.; Pilut, R. (2016). Project DISIRE (H2020) - an idea of annotating of ore with sensors in the KGHM PM S.A. underground copper ore mines, Mineral Engineering Conference (MEC2016), E3S Web of Conferences, Vol. 8, Paper 01058, doi:10.1051/e3sconf/20160801058

[14] Jurdziak, L., Kawalec, W., Król, R. (2018). Study on tracking the mined ore compound with the use of process analytic technology tags, Burduk, A.; Mazurkiewicz, D. (Eds.), Intelligent Systems in Production Engineering and Maintenance - ISPEM 2017, Springer, Cham, 418-427, doi:10.1007/978-3-319-64465-3 40

[15] Malewski, J. (2017). Production of copper as a complex mining and metallurgical processing system in Polish copper mines of the Legnica-Glogów Copper Belt, IOP Conference Series: Earth and Environmental Science, Vol. 95, Paper 042005, doi:10.1088/1755-1315/95/4/042005

[16] Katterfeld, A.; Wensrich, C. (2017). Understanding granular media: from fundamentals and simulations to industrial application, Granular Matter, Vol. 19, Paper 83, 4 pages, doi: $10.1007 / \mathrm{s} 10035-017-0765-\mathrm{y}$

[17] Dai, Y.; Chen, L. S.; Zhu, X.; Liu, H. (2016). Modelling and simulation of a mining machine excavating seabed massive sulfide deposits, International Journal of Simulation Modelling, Vol. 15, No. 2, 377-387, doi:10.2507/IJSIMM15(2)CO10

[18] Kessler, F.; Prenner, M. (2009). DEM - Simulation of conveyor transfer chutes, FME Transactions, Vol. 37, No. 4, 185-192

[19] Cundall, P. A.; Strack, O. D. L. (1979). A discrete numerical model for granular assemblies, Geotechnique, Vol. 29, No. 1, 47-65, doi:10.1680/geot.1979.29.1.47

[20] Di Maio, F. P.; Di Renzo, A.; Trevisan, D. (2009). Comparison of heat transfer models in DEMCFD simulations of fluidized beds with an immersed probe, Powder Technology, Vol. 193, No. 3, 257-265, doi:10.1016/j.powtec.2009.03.002

[21] Fedorko, G.; Ivančo, V. (2012) Analysis of force ratios in conveyor belt of classic belt conveyor, Procedia Engineering, Vol. 48, 123-128, doi:10.1016/j.proeng.2012.09.494

[22] The Engineering Toolbox. Friction and Friction Coefficients, from https://www.engineeringtoolbox.com/friction-coefficients-d_778.html, accessed on 23-12-2017

[23] Rocscience Coefficient of Restitution Table, from https://www.rocscience.com/help/rocfall/ webhelp/RocFall.htm\#baggage/rn_rt_table.htm, accessed on 23-12-2017

[24] Roymechx. Coefficient of Friction, from http://www.roymech.co.uk/Useful_Tables/Tribology/ co_of_frict.htm, accessed on 23-12-2017 